\title{
Optimal Torque Controller for Synchronous Reluctance Motors
}

\author{
Milutin G. Jovanović and Robert E. Betz \\ Department of Electrical and Computer Engineering \\ University of Newcastle, NSW 2308, Australia
}

\begin{abstract}
A low cost software implementation of an angular velocity observer based control scheme for a space vector PWM inverter fed synchironous reluctance motor is presented. A standard saturated machine $d-q$ model neglecting iron losses is used for torque control. Excellent performance using the maximum torque per ampere strategy is confirmed by simulation and experimental results on an axially-laminated machine.
\end{abstract}

Keywords - Synchronous reluctance machine, control, torque control.

\section{INTRODUCTION}

$\mathrm{T}$ ORQUE control of cageless synchronous reluctance machines (Syncrels) is generally accomplished in the following two ways: (1) directly controlling the torque and flux by applying torque vector control (TVC) [1]; or (2) indirectly, through current control [2-8] or combined currentflux PI control in the $d-q$ rotor reference frame $[9,10]$. The main merit of direct control methods is the rapid transient response and robustness which make them very effective for spindle applications. Apart from being sensorless, the versatile TVC algorithm [1] has other important advantages such as: (a) machine-load parameter independent and thus robust; (b) essentially applicable to any brushless machine; and (c) features inherently decoupled torqueflux control suitable for hardware implementation. However, the low speed stability problems caused by voltage integration, stator resistance variations and noise effects represent a serious deficiency of TVC and all flux-observer based control schemes $[9,10]$.

Conventional vector controllers, on the other hand, provide smooth and accurate control over the entire speed range and loading conditions of the Syncrel as the $d q$ control currents are measurable quantities. They enable better machine efficiency (particularly at light loads) [1,2] and, if implemented in analog hardware using high bandwidth

PE-275-EC-0-01-1999 A paper recommended and approved by the IEEE Electric Machinery Committee of the IEEE Power Engineering Society for publication in the IEEE Transactions on Energy Conversion. Manuscript submitted May 29, 1998; made available for printing January 28, 1999. hysteresis current loops [2], faster dynamic response compared to constant flux controllers. However, there is control performance degradation if saturation is ignored in the model $[2,3]$ and an algebraic cross coupling between the $d q$ circuits due to iron losses is left uncompensated [2, $3,9]$. Several decoupling algorithms have been proposed to improve Syncrel transient capabilities $[4,5]$ and efficiency [6-8]. The major drawback of some of this work is again the absence of magnetic saturation [5-7] but also the lack of experimental verification of simulation results $[5,6]$. Clearly, the strong parameter dependence results in indirect torque control not being as simple and robust as stator-flux oriented TVC. An exception to this is the analog controller described in [10]. The insensitivity to both saturation and core loss influences has been achieved by using the $d$-axis flux and the $q$-axis current as control variables.

Unlike the existing control implementations, which are either fully digital (DSP) [3-8], digital-analog [1] or purely analog $[2,9,10]$, the one to be presented in this paper uses a $\mathrm{PC}$ processor and off-the-shelf digital hardware components. This design solution has been chosen mainly to allow maximum flexibility in the test system and because it is more economical than a DSP based configuration. Another nice feature of this platform is the large variety of software development tools available. The implemented control scheme is superior to those neglecting saturation but has the limitation of not compensating for iron loss effects.

\section{CONTROL Algorithm}

The block diagram of a vector control algorithm for the Syncrel is shown in Figure 1 and the layout of the control signal generation board used for its practical implementation is presented in Figure 7. The real-time software was derived from a computer simulation program written in ' $\mathrm{C}$ '. The controller was based on a conventional $d-q$ model including saturation but omitting iron losses.

The functions of the control blocks in Figure 1 in the order of execution through the main loop of the simulation program are as follows. In the real-time code, the content of this loop is a part of the control interrupt service routine.

The phase currents calculator, together with the machine-load simulator, emulates the sampling system for the machine currents. It converts the $d q$ currents sampled over the previous control interval $\left(i_{d_{m}}\right.$ and $\left.i_{q_{m}}\right)$ into the corresponding phase quantities $\left(i_{a_{n}}\right.$ and $\left.i_{b_{m}}\right)$ by applying 


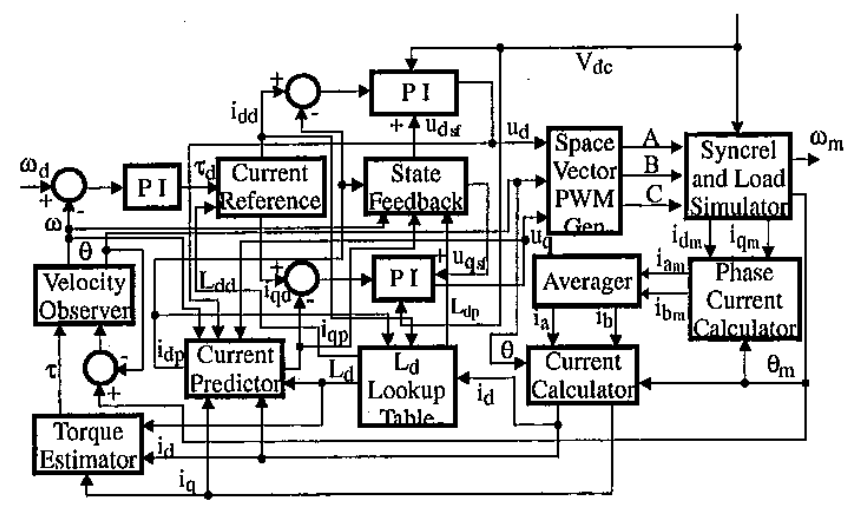

Fig. 1. Algorithmic Structure of Syncrel Control Simulator

a standard inverse Park's transformation. The third phase current can be computed from the remaining two as the test Syncrel has no neutral connection. For the simulation, samples of the rotor $d$-axis electrical angle relative to the phase-a axis $\left(\theta_{m}\right)$, and $i_{d_{m}}$ and $i_{q_{m}}$ are obtained by numerically solving the $d-q$ model equations using a standard 4th order Runge-Kutta integration routine. Clearly the calculation of the three phase currents is redundant in a simulation based on a synchronously rotating machine model. This was done to make the simulation program as close as possible to the real-time code.

The task of the current calculator is to determine the $d q$ currents $\left(i_{d}\right.$ and $\left.i_{q}\right)$ used in the control procedure from the average phase currents $\left(i_{a}\right.$ and $\left.i_{b}\right)$ generated by an averager. It uses a conventional Park's equation and the $d$-axis angle corresponding to the middle of the previous control interval for the conversion. This rotor angle value is taken to account for the $d-q$ frame movement, which can be substantial at higher speeds. It is calculated by averaging the samples from the machine model at the present and previous control sampling instants. In a real system, these simulated samples are replaced by encoder measurements.

All the Syncrel parameters needed for the control calculation (stator resistance, $d q$ inductances and inertia constant) are generated by off-line testing and are summarised in the Appendix. The stator resistance and a dc link voltage $\left(V_{d c}\right)$ are assumed constant (in reality however the latter is varying and it is measured along with two stator currents). The same applies to $L_{q}$ as the low permeance $q$-axis flux paths are mainly through air. Measured values of the machine $d$-axis inductances $\left(L_{d}\right.$ and $\left.L_{d}^{\prime}=d L_{d} / d i_{d}\right)$ are stored in look-up tables.

A high performance load model based observer algorithm [11] is used to obtain accurate predictions of the rotor angular velocity $(\omega)$ and position $(\theta)$ for the beginning of the next control interval. The observer inputs are the position at the present control sampling instant $\left(\theta_{m}\right)$ from the model (in reality, an encoder output) and the estimated torque $\tau=3\left(L_{d}-L_{q}\right) i_{d} i_{q}$ from the torque estimator. The closed-loop configuration in Figure 1 is achieved by feeding back the last observed position (from the previous control interval). This observer design has significant advantages over conventional low pass filters and moving averagers [11].

The function of the current predictor block is to predict the machine $d q$ currents $\left(i_{d p}\right.$ and $i_{q p}$ ) one control interval forward from their actual values $\left(i_{d}\right.$ and $\left.i_{q}\right)$ using the outputs of the current PI regulators evaluated in the previous control interval $\left(u_{d}\right.$ and $u_{q}$ ). Note that $i_{d p}$ and $i_{q p}$ are the feedback currents i.e. the control variables due to predictive nature of the current controller. They are calculated using Euler approximations of the model voltage differential equations :-

$$
\left.\begin{array}{c}
i_{d p}=i_{d}+\frac{u_{d l}-R i_{d}+\omega L_{q} i_{q}}{L_{d}\left(i_{d}\right)+L_{d}^{\prime}\left(i_{i}\right) i_{i d}} \Delta \\
i_{q p}=i_{q}+\frac{u_{q}-R i_{i^{\prime}}-\omega L_{d i} i_{d i}}{L_{q}} \Delta
\end{array}\right\}
$$

A simple speed PI algorithm with the integrator antiwindup is executed next in the control flow to generate the desired electromagnetic torque $\left(\tau_{d}\right)$ required from the machine. $\tau_{d}$ is limited to a value corresponding to the rated current, this being precomputed by Matlab ${ }^{\circledR}$ using the steady-state model equations for the maximum torque per ampere control strategy. The optimal $i_{d d}$ vs $\tau_{d}$ characteristic, generated in a similar manner, is stored in a look-up table and is used by the current reference generator for determining the $d q$ current references ( $i_{d d}$ and $\left.i_{q d}\right)$.

The purpose of the state feedback block is to eliminate the adverse effect of the machine rotational voltages on the performance of the two current PI controllers (one for each rotor axis). In the absence of this feedback significant cross coupling between the $d$ and $q$ axes would occur and the integrators would have large values on them to counteract the machine back emf. Therefore, the block generates the feedforward compensation voltages $u_{d_{s f}}=-\omega L_{q} i_{q p}$ and $u_{q_{s, f}}=\omega L_{d}\left(i_{d p}\right) i_{d p}=\omega L_{d p} i_{d p}$ which are then added to the PI output to overcome disturbances. The resultant unconstrained voltages are passed through the limiter with a circular limit of $V_{d c} / \sqrt{3}$ to obtain those to be applied to the machine $\left(u_{d}\right.$ and $\left.u_{q}\right)$.

The PWM generator implements a conventional space vector based PWM algorithm with double edged modulation [12] and inverter dead-time compensation [13]. It accepts the required $d q$ voltage inputs from the current controller and then works out the switching pattern and switching times of inverter legs so that the average voltage vector is the desired. In the real system, the switching times are programmed into the timers that control the firing of IGBT's (Figure 7). Note also that for the simulation purposes the inverter transistors are assumed to be ideal switches and the value of the dead-time is set to zero. In reality, however, this value is programmed into an overlap timer which protects against shoot through (Figure 7).

\section{Computer Simulation Studies}

The following performance results are obtained by running the simulation program in Figure 1 at a $3-\mathrm{kHz}$ control rate (which is also the switching frequency of an individual inverter leg). In the experimental controller this 

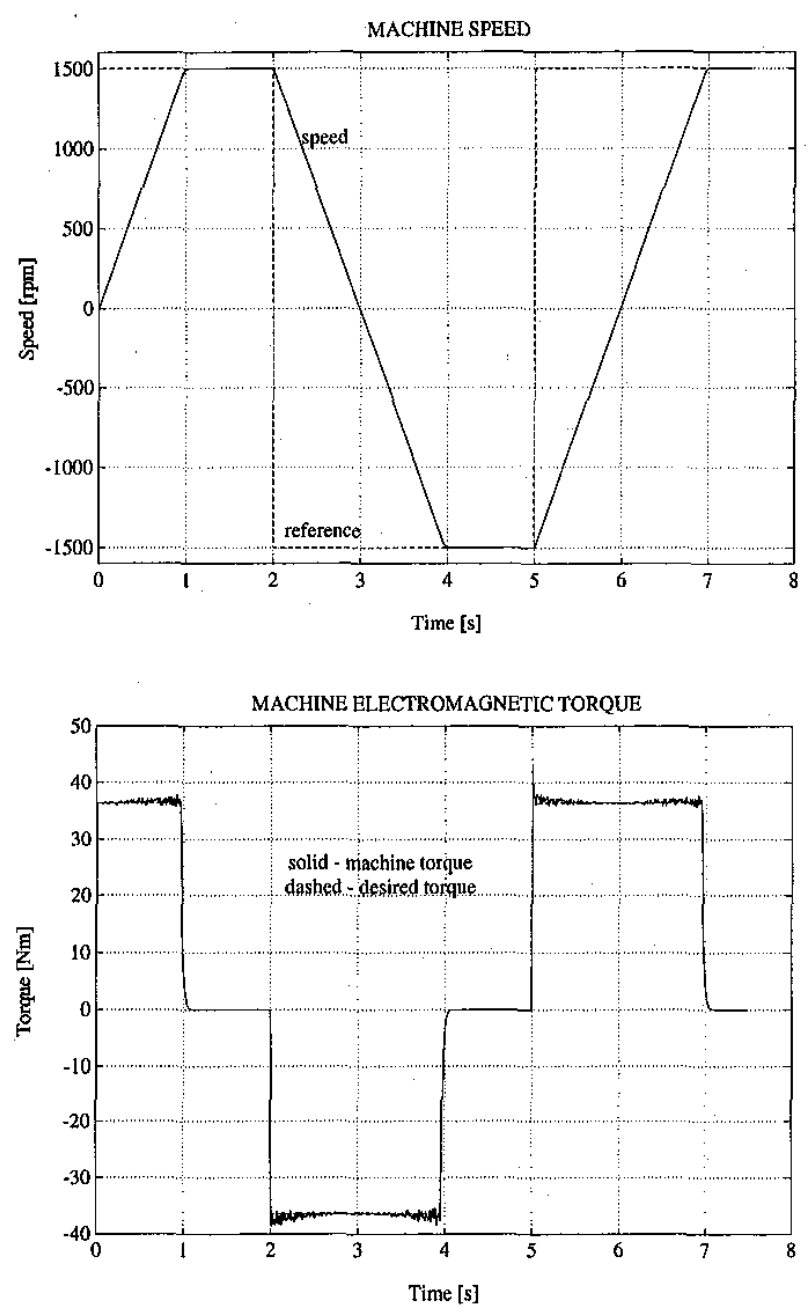

Fig. 2. Simulated speed and torque performance of the machine

is programmed into an interrupt timer (Figure 7). A dc link voltage value corresponding to a rectified $415-\mathrm{V}, 50-\mathrm{Hz}$ mains voltage in the real system was assumed in the calculations. The control objective was to allow the speed of an inertially loaded machine to track the desired reference using the maximum torque per ampere strategy.

Figure 2 displays the speed and average torque of the machine during speed control. The top plot is the Syncrel response to a changing speed reference between \pm 1500 $\mathrm{rpm}$. The excellent controller performance is obvious. It can be seen that the machine moves between \pm 1500 -rpm in about 2-s with no overshoot. The same time can be approximately determined directly from the load model equation bearing in mind that the machine is operating at the torque limits. This leads to the speed change being virtually linear.

The bottom plot in Figure 2 shows that the machine torque accurately follows the reference value with very little overshoot. Small variations under transient conditions when the machine is fully fluxed result from the inaccu-
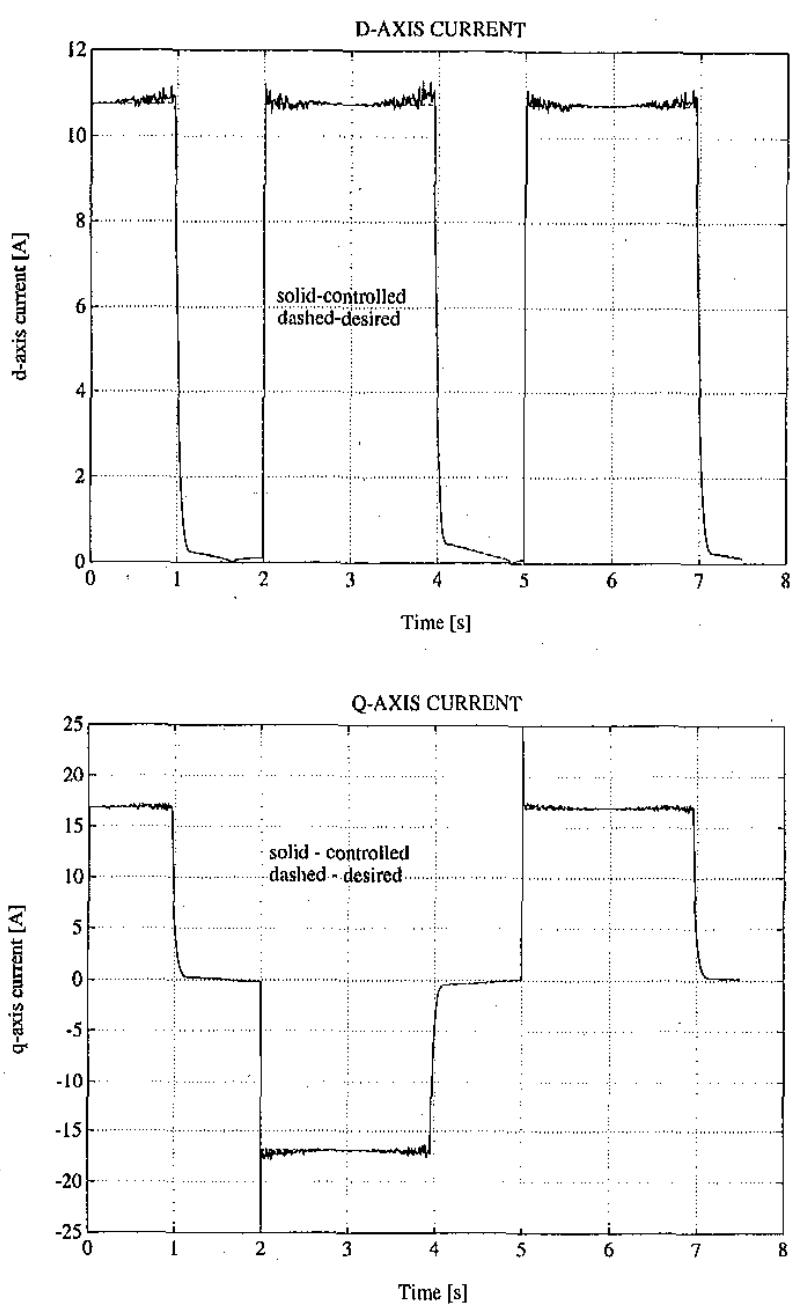

Fig. 3. Average d-q currents from simulation

racies in the control current predictions and consequent errors in the applied voltages. Note also the switching ripples in the actual torque waveform. The prediction errors and torque ripple are larger at higher speeds and currents because of the increased influence of rotational voltages. In steady-state, on the other hand, the torque characteristic is smooth despite the high speed as the control prediction is then much better due to the absence of flux and hence induced voltages in the unloaded machine.

The $d q$ currents needed for the machine to produce the torque in Figure 2 are shown in Figure 3. It can be observed that there is very good tracking of desired trajectories which demonstrates the effectiveness of the torque controller. The effects of prediction errors and inverter switching are visible during transients at higher speeds. They manifest themselves in the fluctuations and slight drifting of the actual waveforms from the desired ones. These variations can be reduced by increasing the PI gains of the current loops. However, excessive increase may lead to instability of the control algorithm. 


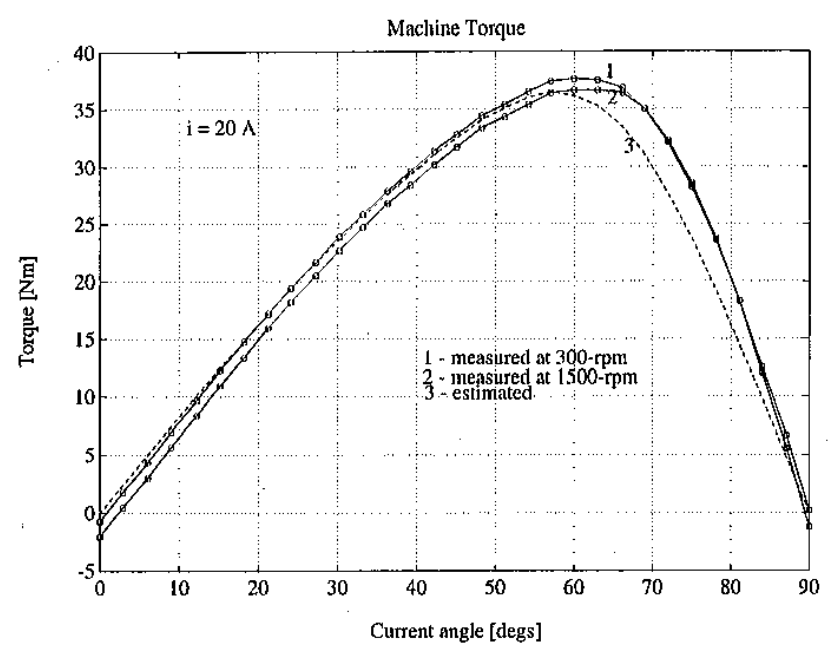

Fig. 4. Torque performance of the fully loaded Syncrel

The close similarity between the torque and $q$-axis current waveforms is evident from Figures 2 and 3 . This result is expected as the current response is much faster in the $q$-axis than in the $d$-axis $\left(L_{q}<<L_{d}\right)$ and consequently the $q$-axis current is essentially responsible for the torque dynamics. The function of the $d$-axis current is primarily to establish flux in the machine. It is therefore always kept positive (or zero) regardless of the torque sign determined by the $q$ current.

Another interesting observation from Figure 3 is the little current deviations from zero at the steady state speed of the machine (1500-rpm). This can be explained by the minor control inaccuracies of the speed PI regulator resulting in the small non-zero command torque value (hardly visible in Fig. 2 due to scaling). It should be noted here that windage and bearing friction are ignored in the simulation.

\section{EXPERIMENTAL RESUlTS}

In order to verify the high performance of the optimal torque control scheme obtained from the simulation, experimental results have been generated for a $5.8-\mathrm{kW}$ axiallylaminated Syncrel. Most of the variables used to plot the results are available directly from the control program.

An angular velocity observer was shown to have high accuracy as the speed estimates were in excellent agreement with the precision torque transducer measurements. Therefore, the observed speed will be considered to be the actual machine speed. Unfortunately, torque dynamic response could not be recorded on a digital oscilloscope for the reasons discussed in the Appendix. However, the steady-state torque predictions from the control algorithm were fairly accurate as the Syncrel prototype had small iron losses. This is confirmed by the plots in Figure 4 produced for the test Syncrel operated under open-loop speed control at the rated current.

Figure 4 illustrates a good agreement between the measured and estimated torque characteristics around the opti- mal current angle of approximately $60^{\circ}\left(\approx 58^{\circ}\right.$ predicted $)$. Therefore, it is reasonable to assume that these curves will also correspond well under transient conditions as the machine current is then maximum. Notice from the same figure the effects of torque control without iron loss compensation. The machine is obviously developing less torque at higher speeds and negative (stalling) torque at zero current angle $[4,14]$. The torque production at $1500-\mathrm{rpm}$ is however not significantly different from that at 300-rpm.

The Syncrel speed and estimated electromagnetic torque while varying the speed reference between \pm 1500 -rpm are shown in Figure 5. Smooth response and effective speed control at the desired value are clearly demonstrated in the top plot the speed reversal occuring in about 2.1-s with no overshoot. Similar results $(2.0-\mathrm{s})$ were obtained by simulation (Fig. 2). The essential differences between the test and simulated waveforms are the non-linear variation of the actual speed and better dynamic performance of the machine in the regenerative compared to the motoring operating mode. It can be seen from Figure 5 that the rate of change of speed is higher during braking than while starting because of the larger Syncrel torque in the first case. This unsymmetrical transient response of speed (and torque) is mainly a consequence of an uncompensated cross coupling between the $d q$ axes caused by core losses $[4,7,10]$.

The experimental torque curve in the bottom plot of Figure 5 confirms the observations made about the corresponding simulated characteristic in Figure 2. However, unlike the simulation, the torque values are clearly not zero at 1500-rpm, even though the machine is unloaded. Discrepancies between the simulation and test results are due to the presence of iron and mechanical losses in a real machine, model and parameter knowledge inaccuracies, as well as other practical effects.

The machine currents (average per control interval) in the $d q$ axes required to achieve a speed reversal between \pm 1500 -rpm are presented in Figure 6. The torque and $q$-axis current waveforms are almost exactly the same in shape as predicted by the simulation studies. Also, switching ripple in the $q$-axis current waveform is larger than in the $d$-axis counterpart due to much lower inductance (although this is difficult to see with the scale on the diagram). Furthermore, notice that the $d q$ currents are approximately equal at constant speed. This means that the current angle is near the ideal optimum i.e. $45^{\circ}$, since the machine is unsaturated, and has low core losses.

On the other hand during the transient periods the $q$ axis current is substantially larger than the $d$-axis current. The current angle has been increased above $45^{\circ}$ to maximise the torque from the fully saturated machine. This angle rise mostly results from saturation as the iron loss effects are swamped by saturation influences at high current values (Figure 4). Therefore, one may conclude that the $d q$ currents are accurately controlled so that the torque per ampere is optimised under all operating conditions of 

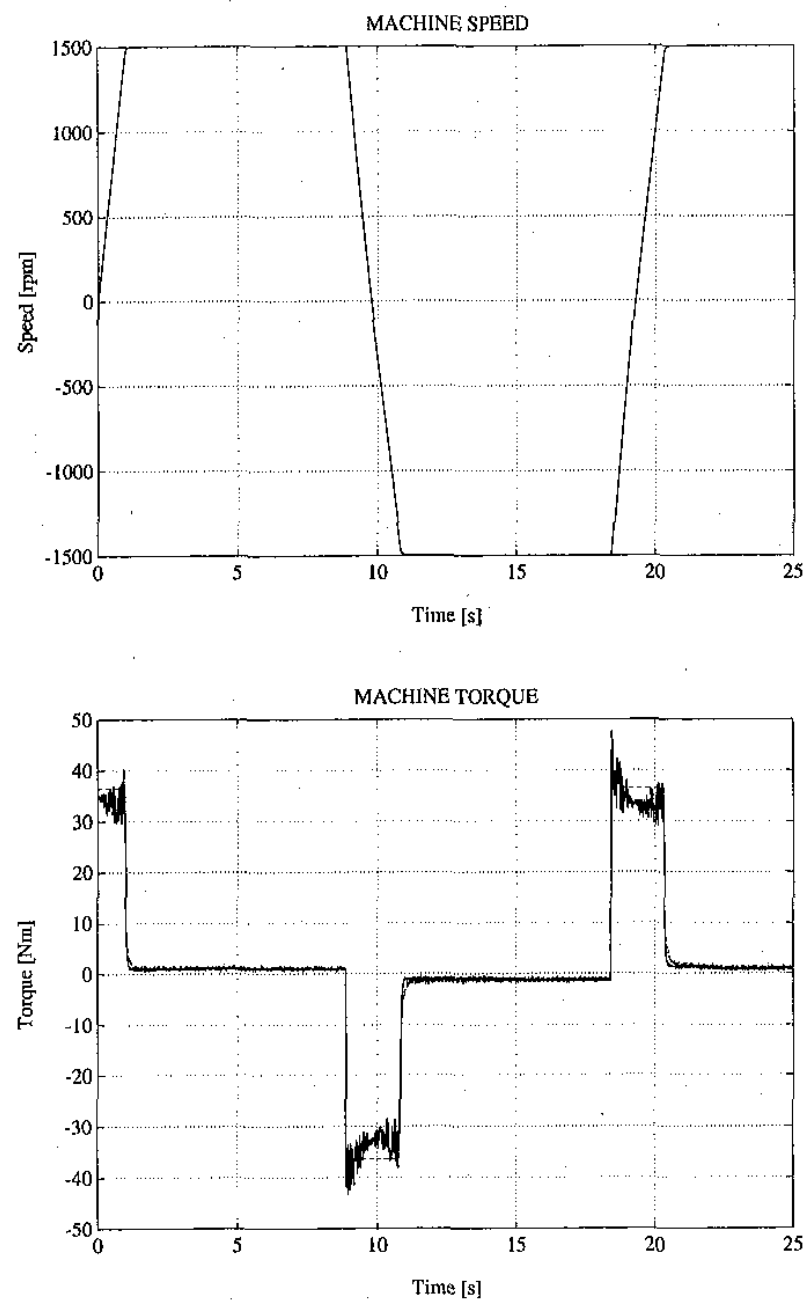

Fig. 5. Test Syncrel Performance : dashed - desired, solid - actual

the machine.

\section{CONCluSIONS}

The contribution of this paper is the presentation of practical implementation and computer simulation issues of a Syncrel vector control algorithm and the discussion of experimental and simulation results demonstrating its high accuracy on an axially-laminated machine. The scheme has been implemented entirely in software using a Pentium PC and custom built hardware. The advantages of this platform are its low cost, excellent software tools, and flexibility in a research environment.

The results shown have confirmed the effectiveness of applying a saturated $d-q$ model for control of Syncrels having relatively low iron losses. Smooth speed response, using a maximum torque per ampere control objective, has been demonstrated during starting, speed reversal and steady state. The machine performance has been slightly compromised at larger speeds and currents by the uncompensated iron loss effects. A compensated controller design is under
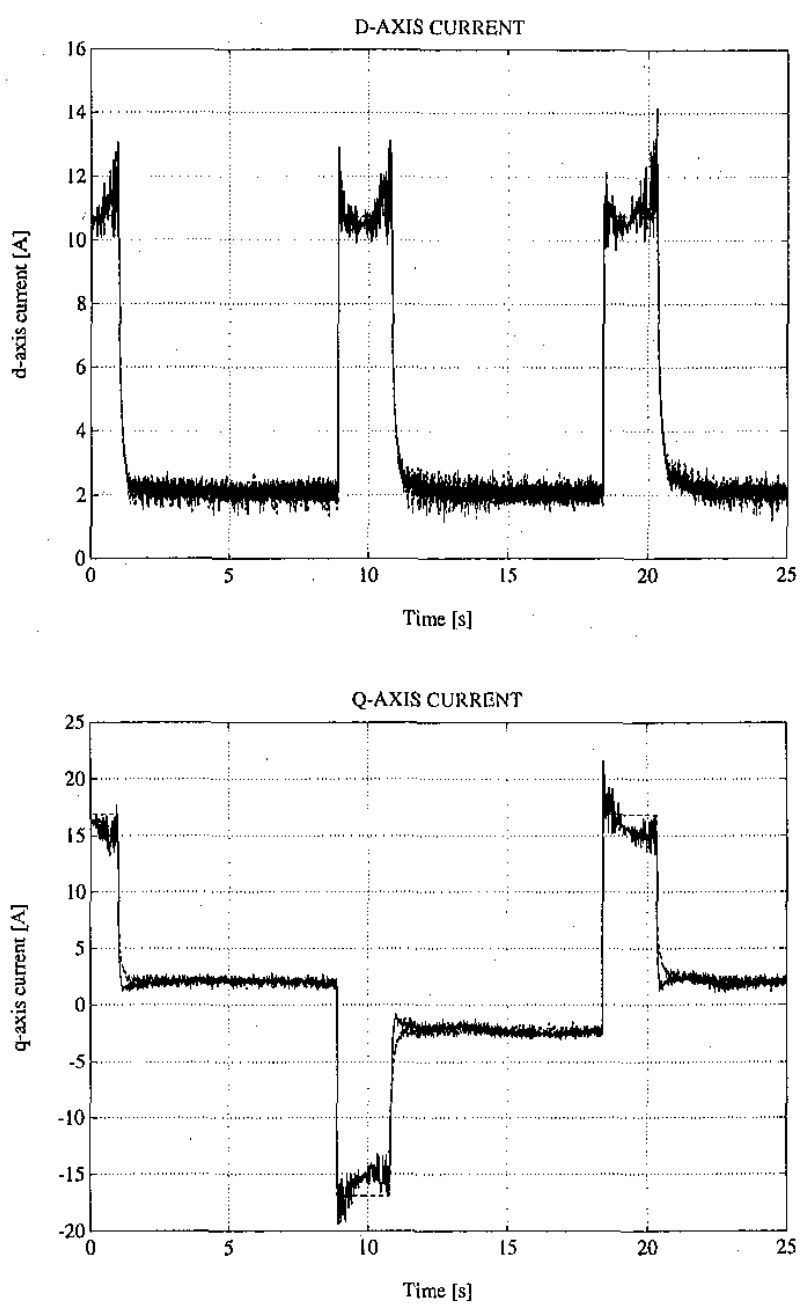

Fig. 6. Machine currents while speed reversal : solid line-measured, dashed line - desired

development and will be presented in a future paper.

\section{APPENDIX}

\section{DRIVE System OUTLINE}

A cageless 4-pole axially-laminated Syncrel with a conventional $7.5-\mathrm{kW}$ induction machine stator and a supply inverter using Mitsubishi IGBT power modules were both designed and built in the Department workshop. The rotor construction is similar to that from the University of Glasgow in Scotland [14]. The optimum torque performance parameters of the machine are listed in Table I.

The torque transducer (from Vibro-Meter ${ }^{\circledR}$ in Switzerland) has excellent frequency response $(\approx 1-\mathrm{kHz})$ making it suitable for dynamic testing. However, it was impossible to capture the machine torque waveform on a digital oscilloscope due to very noisy analog output signals from the transducer display unit. This noise resulted from capacitive earth-leakage currents (induced by inverter switchings) flowing through the transducer housing. 


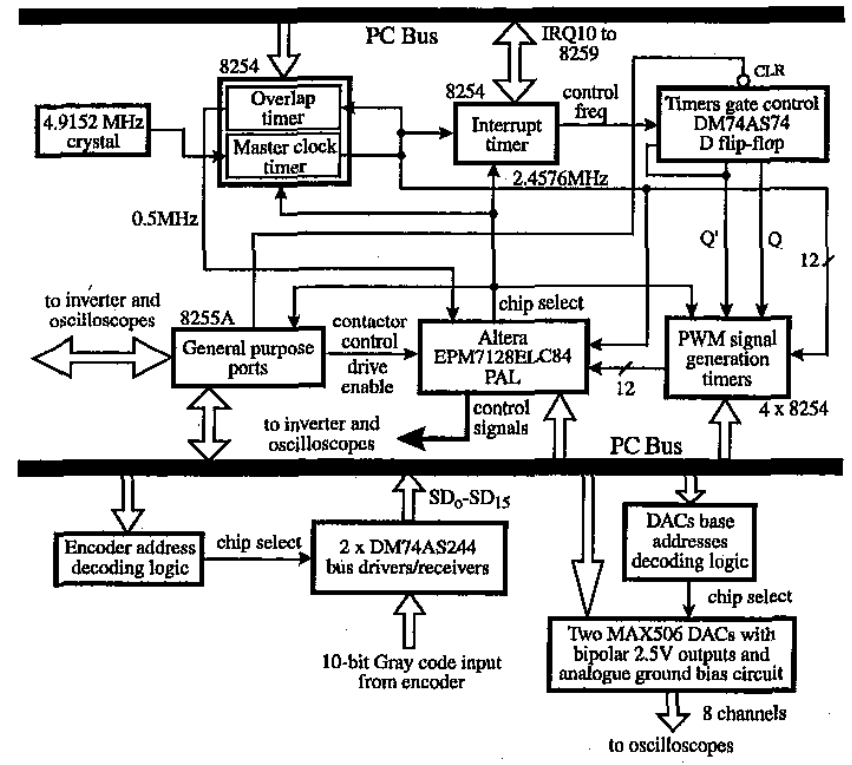

Fig. 7. Control signal generation board - simplified block diagram

The DC load machine was fed from a Ward-Leonard based supply without electronic control. This limitation makes the existing test system suitable mainly for conducting steady-state or locked rotor tests but not for Syncrel/controller transient testing. The development of a DSP based control computer and a supply converter for the $\mathrm{DC}$ machine is in progress the objective being to build a dynamic dynamometer capable of emulating characteristics of the representative industrial loads.

The inverter hardware and a 10-bit absolute position encoder are interfaced to the CPU bus of a Pentium PC by means of the two programmable I/O boards with interrupt capabilities - a custom made control signal generation board (Figure 7) and an off-the-shelf 12-bit multiplexed A/D data conversion board. Details of the design and functionality of these boards can be found in [15].

TABLE I

Test Syncrel Parameters

\begin{tabular}{||c||c||}
\hline \hline Power & $5.8-\mathrm{kW}$ \\
Current (rms) & $14.3-\mathrm{A}$ \\
Current angle & $60^{\circ} \mathrm{elec}$ \\
Speed & $1500-\mathrm{rpm}$ \\
\hline \hline$L_{d}$ unsaturated & $88.9-\mathrm{mH}$ \\
$L_{d}$ saturated & $76.8-\mathrm{mH}$ \\
$L_{q}$ & $9.8-\mathrm{mH}$ \\
Inertia (total) & $0.23-\mathrm{kgm}^{2}$ \\
$R_{d c}$ (cold) & $0.6-\Omega$ \\
\hline
\end{tabular}

\section{REFERENCES}

11) R.Lagerquist, 1.Boldea, and T.J.E.Miller, "Sensorless control of the synchronous reluctance motor," IEEE Transactions on Industry Applications, vol. 30, no. 3, pp. 673-682, May/June 1994.

[2] A.Chiba and T.Fukao, "A closed-loop operation of super highspeed reluctance motor for quick torque response," IEEE Trans- actions on Industry Applications, vol. 28, no, 3, pp. 600-606, 1992.

[3] R.E.Betz, R.Lagerquist, M.Jovanovic, T.J.E.Miller, and R.H.Middleton, "Control of synchronous reluctance machines," IEEE Transactions on Industry Applications, vol. IA-29, no. 6 , pp. 1110-1122, 1993.

[4] L.Xu and J.Yao, "A compensated vector control scheme of a synchronous reluctance motor including saturation and iron losses," IEEE' Transactions on Industry Applications, vol. 28, no, 6 pp. 1330-1338, 1992.

[5] K.Uezato, T.Senjyu, and Y.Tomori, "Modelling and vector control of synchronous reluctance motors including stator iron loss," IEEE Transactions on Industry Applications, vol. 30, no. 4, pp. 971-976, 1994.

[6] J.E.Fletcher, B.W.Williams, and T.C.Green, "Efficiency aspects of vector control applied to synchronous reluctance motors," Proc. IEEE-IAS Annual Meeting, pp. 294-300, Orlando, Florida, Oct 1995.

[7] S. J. Kang and S. K. Sul, "Efficiency optimized vector control of synchronous reluctance motor," IEEE-IAS Annual Meeting, pp. 117-121, San Diego, California, October 1996.

[8] T.Matsuo, A.El-Antably, and T.A.Lipo, "A new control strategy for optimum efficiency operation of a synchronous reluctance motor,", IEEE-IAS Annual Meeting, pp. 109-116, San Diego, California, October 1996.

[9] A.Fratta and A.Vagati, "A reluctance motor drive for high dynamic performance applications," IEEE Transactions on Industry Applications, vol. 28, no. 4, pp. 873-879, 1992.

[10] A.Vagati, M.Pastorelli, and G.Franceschini, "High performance control of synchronous reluctance motor," IEEE-IAS Annual Meeting, San Diego, California, pp. 295-303, October 1996.

[11] R.D.Lorenz and K.W.VanPatten, "High-resolution velocity estimation for all-digital, ac servo drives," IEEE Transactions on Industry Applications, vol. 27, pp. 701-705, July/August 1991.

[12] H.W.VanDerBroeck, I.C.Skudelny, and G.V.Stanke, "Analysis and realisation of a pulsewidth modulator based on voltage space vectors," IEEE Transactions on Industry Applications, vol. 24 no. 1, pp. 142-150, January/February 1988.

[13] R.B.Sepe and J.I.Lang, "Inverter nonlinearities and discretetime vector current control," IEEE Transactions on Industry Applications, vol. 30, pp. 62-70, January/February 1994.

[14] W.L.Soong, D.A.Staton, and T.J.E.Miller, "Design of a new axially-laminated interior permanent magnet motor," IEEE Transactions on Industry Applications, vol. 31, Pp. $358-367$, March/April 1995.

[15] M. G. Jovanović, R. E. Betz, and D. Platt, "Sensorless vector controller for a synchronous reluctance motor," IEEE Transactions on Industry Applications, vol. 34, pp. 346-354, March/April 1998.

Milutin G. Jovanović received the Dipl.Eng and M.E.E. degrees from University of Belgrade, Belgrade, Yugoslavia, in 1987 and 1991 respectively, and the Ph.D. degree from the University of Newcastle, Newcastle, Australia, in 1997.

$\mathrm{He}$ is currently a Lecturer in the School of Engineering, Liverpool John Moores University, Liverpool, UK. His main interests are in the areas of electrical machines and drives, industrial electronics and power systems.

Dr. Jovanović is a member of the Industrial Drives Committee of the IEEE Industry Applications Society.

Robert E. Betz (M'92) received the B.E., M.E. and Ph.D. degrees from the University of Newcastle, Newcastle, Australia in 1979, 1982 and 1984 respectively.

He is currently a Senior Lecturer in the Department of Electrical and Computer Engineering, University of Newcastle. His major interests are electrical machine drives, real-time operating systems, and industrial electronics.

Dr. Betz is a member of the Industrial Drives Committee of the IEEE Industry Applications Society. 